\title{
Optimizing the Properties of Polyether Based Polyurethane Foam
}

\author{
F. O. Aramide ${ }^{1 *}$, P. O. Atanda ${ }^{2}$, E. O. Olorunniwo ${ }^{2}$ \\ ${ }^{1}$ Metallurgical and Materials Engineering Department, Federal University of Technology, Akure, Nigeria \\ ${ }^{2}$ Materials Science and Engineering Department, Obafemi Awolowo University, Ile-Ife, Nigeria \\ Email: fat2003net@yahoo.com, foaramide@futa.edu.ng, atandapo@yahoo.com,segun_nniwo@yahoo.com
}

Received July 4, 2013; revised August 25, 2013; accepted September 3, 2013

Copyright (C) 2013 F. O. Aramide et al. This is an open access article distributed under the Creative Commons Attribution License, which permits unrestricted use, distribution, and reproduction in any medium, provided the original work is properly cited.

\begin{abstract}
Effect of different chemicals and additives used in producing polyester foam was investigated. Reference samples were produced from polyol, toluene di isocyanate (TDI), amine stannous octoate distil water, and silicone oil using laboratory mix formulation based on $500 \mathrm{~g}$ polyether based polyol. Other samples were produced by consecutively varying the content of all the additives with the exception of polyol. Standard sample dimensions for density test, indentation test, compression set test, tensile strength and elongation tests were produced from the samples. The various tests were carried out on the samples using the ASTM-D3574 standards. It was observed that the degree of indentation affects the value of indentation hardness and increasing the percentage content of TDI results in acceptable compression set value for the polyester samples. It was concluded that Holding all other parameters constant, reducing the water content and increasing the TDI content will yield polyester foam of optimum properties.
\end{abstract}

Keywords: Hardness; Polyester Foam; Compression Set and Optimum Properties

\section{Introduction}

Polyester are generally referred to as stable polymers and they are reaction products of etherification of di- or polyhydric alcohol with di- or poly-basic acids and anhydrides. They are broadly categorized into saturated and unsaturated polyesters [1]. Unsaturated polyesters are widely used in the composite industry. They can provide excellent mechanical and chemical properties, good chemical and weather resistance, and a low cost. Further advantages of unsaturated polyester resins over other thermosetting resins for they are easy to handle, can be pigmented, and can be easily filled and fibre reinforced in a liquid form [2]. These are normally produced in three steps; the polycondensation reaction of di-alcohol, an acid anhydride and a di-acid into a pre-polymer resin. This is followed by the addition of monomer and lastly, curing of the polyester resin into a thermoset polymer by an organic peroxide [3].

Polyester materials are used as chemical resistant finishes for interiors of chemical and petrochemical storage tanks [4]. They are also utilized as biomaterials as synthetic vascular grafts being intensively used in vascular

\footnotetext{
"Corresponding author.
}

system surgery [5], among others they are used as bypasses to derive blood circulation or to replace failed blood vessels [6-10]. Many researchers have done wonderful work on polyester material [11-14] but very little has actually focused on optimizing the property of polyester foam by investigating the influence of additives on the properties of the resulting polyester foam. This research endeavours to focus in this direction.

\section{Materials and Methods}

The materials for this work are; polyol, toluene-diisocyanate (TDI), amine, distil water, silicone oil, stannous octoate, moulding box lined with thin plastic sheet, electrically operated stirrer, electronic balance and stop watch.

\subsection{Sample Preparation}

Polyol and toluene-diisocyanate (TDI) were weighed into separate containers. This was followed by weighing distil water, silicone oil and amine sequentially into a container, mixed thoroughly and then poured into the earlier measured polyol. This was mixed thoroughly for 30 seconds followed by the addition of stannous octoate while mix- 
ing for the about 10 seconds. Finally the measured TDI was added, rapidly mixed for 5 seconds and then carefully and quickly poured into the prepared mould box. From this point, the stop watch was used to monitor and record the rising time. On attainment of foam full rise, the solidified foam was removed from the mould box for further experimentation.

\subsection{Mathematical Formulation of Reference Sample}

For the purpose of this work, a reference sample of density $23 \mathrm{Kgm}^{-3}$ was selected. In order to achieve this reference sample's density, the weights of various additives to be added were calculated using laboratory mix formulation, fixing the mass of polyol at $500 \mathrm{~g}$ [11-13]. The formulation for the reference sample is show in Table 1.

Other various samples used for this research work were produced by varying the mass of an additives used at time with the exception of polyol by $\pm 20 \%$ of the weight used for the additive, while the other remain constant. Through this all other samples were separately produced.

\subsection{Sample Machining}

From each of the different samples produced, regular shaped foam blocks were produced to make them suitable for machining. The machining of the samples produced standard test sample's dimensions for investigating the mechanical properties of the samples.

\subsection{Investigation of Various Properties}

Three test samples were used to measure each property and the average value was calculated and recorded. Each of the tests was carried out as outlined in the ASTMD3574 [13-16].

\subsubsection{Density}

Flat surface cuboids (test pieces) were cut out from each of the samples of foam produced. The dimensions of each test piece is measured in meters, from these the volume was calculated. Then the mass of the test piece was measured, using the electronic weighing balance, the

Table 1. Formulation for the reference sample.

\begin{tabular}{cc}
\hline Additive & Actual mass $(\mathrm{g})$ \\
\hline Polyol & 500 \\
TDI & 262 \\
Distil water & 21 \\
Silicone oil & 5 \\
Stannous octoate & 0.9 \\
Amine & 0.9 \\
\hline
\end{tabular}

value of this was recorded in kilograms. From the data generated the density of each test piece was calculated and recorded.

\subsubsection{Indentation Hardness Index Test}

The indentation hardness index (IHI) of foam is a measurement of its load bearing ability. This is the force required to depress a small circular plate into the foam.

The test sample is placed on the support plate and adjusted so to locate the centre of the sample below the centre of the indenter. The operation of the indentation machine was initially set to $65 \%$ of the sample's thickness and the a force of $5 \mathrm{~N}$ (Newton) was applied to the test area; on getting to the $65 \%$ of the sample's thickness, the process stopped and sample was allowed to rise up under the indenter for 60 seconds then the hardness value was read off the calibrated scale on the machine. The machine was then set to $60 \%$ of the sample's thickness and the process was repeated but this time the sample was allowed to rise under the indenter for 45 seconds and hardness value was measured and recorded.

\subsubsection{Compression Set Test}

The test sample of dimensions $50 \mathrm{~mm} \times 50 \mathrm{~mm} \times 25 \mathrm{~mm}$ was cut out. The initial thickness of the sample was measured and recorded. The sample was placed between the horizontal plates of a compression device; each of the horizontal plates has a greater surface area than the test sample. The compression plates were so arranged while holding the sample to be parallel to each other, and the space between them was adjusted to the required deflected height.

The sample was compressed to $75 \%$ of its original thickness, maintained at this known condition for 72 hours. The sample was removed, allowed to recover for 30 minutes and the final thickness was measured and recorded. The compression set is calculated from:

$$
\text { Compression set }=100\left(\mathrm{~T}_{\mathrm{o}}-\mathrm{T}_{\mathrm{r}}\right) / \mathrm{T}_{\mathrm{o}}
$$

where: $T_{0}$ is the original thickness of sample

$T_{r}$ is the thickness of sample after recovery

\subsubsection{Tensile Strength}

This test gives information on the elasticity of the foam, it also indicates the strength of foam sample under tension.

The tensile tests were performed on various samples using Monsanto tensometer. The fracture load for each sample was noted as well as the diameter at the point of fracture and the final gauge length. The initial diameter and initial gauge length for each sample was noted before uniaxial load. From the generated data the ultimate tensile strength and percentage elongation of each sample was calculated. 


\section{Results and Discussions}

Tables 2-5 show the effects of varying additive content on the density of the polyester sample; the effects of varying additive content on the tensile property of the polyester sample; the effects of varying additive content on the indentation hardness index of the polyester sample and the effects of varying additive content on the compression set of the polyester sample respectively. Furthermore, Figures 1-5 show the effect of varying additives on the density of the polyester sample; the effect of varying additives on the tensile strength of the polyester sample; the effect of varying additives on the percentage elongation of the polyester sample; the effect of varying additives on the hardness of the polyester sample and the effect of varying additives on the compression set value of the polyester sample.

Table 2. Effects of varying additive content on the density of the polyester sample.

\begin{tabular}{|c|c|c|c|}
\hline $\begin{array}{l}\text { Varying } \\
\text { Additive }\end{array}$ & Mass (Kg) & Volume $\left(\mathrm{m}^{3}\right)$ & $\begin{array}{l}\text { Density } \\
\left(\mathrm{Kgm}^{-3}\right)\end{array}$ \\
\hline$-20 \%$ TDI & 0.161 & 0.00705 & 22.8 \\
\hline$-10 \%$ TDI & 0.164 & 0.00710 & 22.94 \\
\hline$+10 \%$ TDI & 0.162 & 0.00719 & 22.53 \\
\hline$+20 \%$ TDI & 0.153 & 0.00728 & 21.02 \\
\hline$-20 \%$ Distil Water & 0.144 & 0.00811 & 17.75 \\
\hline$-10 \%$ Distil Water & 0.152 & 0.00802 & 18.95 \\
\hline$+10 \%$ Distil Water & 0.158 & 0.00814 & 19.41 \\
\hline$+20 \%$ Distil Water & 0.165 & 0.0831 & 19.85 \\
\hline$-20 \%$ Amine & 0.156 & 0.00679 & 22.9 \\
\hline$-10 \%$ Amine & 0.153 & 0.00661 & 23.11 \\
\hline$+10 \%$ Amine & 0.165 & 0.00689 & 23.94 \\
\hline$+20 \%$ Amine & 0.168 & 0.00709 & 23.6 \\
\hline $\begin{array}{c}-20 \% \text { Stannous } \\
\text { Octoate }\end{array}$ & 0.174 & 0.00688 & 25.3 \\
\hline $\begin{array}{c}-10 \% \text { Stannous } \\
\text { Octoate }\end{array}$ & 0.168 & 0.00679 & 24.74 \\
\hline $\begin{array}{c}+10 \% \text { Stannous } \\
\text { Octoate }\end{array}$ & 0.159 & 0.00683 & 23.27 \\
\hline $\begin{array}{c}+20 \% \text { Stannous } \\
\text { Octoate }\end{array}$ & 0.163 & 0.00695 & 23.5 \\
\hline $\begin{array}{c}-20 \% \\
\text { Silicone oil }\end{array}$ & 0.167 & 0.00742 & 22.5 \\
\hline $\begin{array}{l}\quad-10 \% \\
\text { Silicone oil }\end{array}$ & 0.161 & 0.00708 & 22.74 \\
\hline $\begin{array}{l}\quad+10 \% \\
\text { Silicone oil }\end{array}$ & 0.156 & 0.00674 & 23.15 \\
\hline $\begin{array}{l}\quad+20 \% \\
\text { Silicone oil }\end{array}$ & 0.161 & 0.00709 & 22.7 \\
\hline Reference Sample & 0.218 & 0.00939 & 23.2 \\
\hline
\end{tabular}

Table 3. Effects of varying additive content on the tensile property of the polyester sample.

\begin{tabular}{ccc}
\hline Varying Additive & Elongation $(\%)$ & $\begin{array}{c}\text { Tensile Strength } \\
\left(\mathrm{Nmm}^{-2}\right)\end{array}$ \\
\hline$-20 \%$ TDI & 157.5 & 110.2 \\
$-10 \%$ TDI & 145.4 & 102.4 \\
$+10 \%$ TDI & 45.8 & 102.4 \\
$+20 \%$ TDI & 50.3 & 102.4 \\
$-20 \%$ Distil Water & 35.9 & 102.4 \\
$-10 \%$ Distil Water & 33.6 & 102.4 \\
$+10 \%$ Distil Water & 111.7 & 78.7 \\
$+20 \%$ Distil Water & 95.8 & 86.6 \\
$-20 \%$ Amine & 115.9 & 181.1 \\
$-10 \%$ Amine & 117.6 & 173.2 \\
$+10 \%$ Amine & 110.3 & 133.8 \\
$+20 \%$ Amine & 95.5 & 125.9 \\
$-20 \%$ Stannous Octoate & 86.5 & 149.6 \\
$-10 \%$ Stannous Octoate & 85.3 & 149.6 \\
$+10 \%$ Stannous Octoate & 82.8 & 133.8 \\
$+20 \%$ Stannous Octoate & 86.0 & 141.7 \\
$-20 \%$ Silicone oil & 77 & 118.1 \\
$-10 \%$ Silicone oil & 71.5 & 118.1 \\
$+10 \%$ Silicone oil & 87.6 & 125.9 \\
$+20 \%$ Silicone oil & 81.2 & 118.1 \\
Reference Sample & 129.7 & 165.4 \\
\hline
\end{tabular}

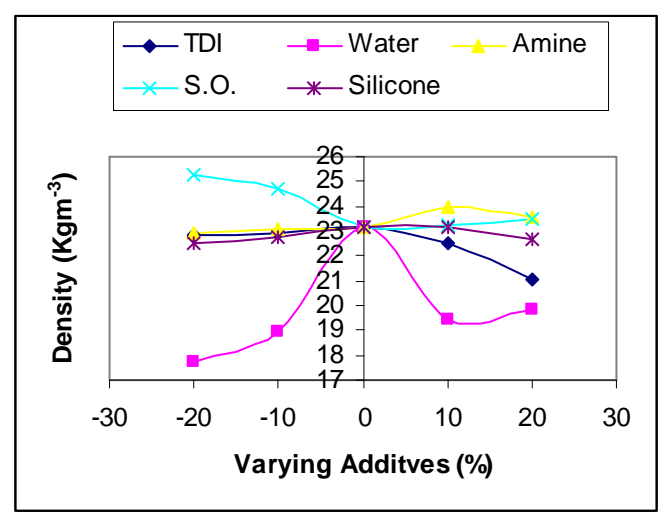

Figure 1. Effect of varying additives on the density of the polyester sample.

From Figure 1 and Table 2 the effect of varying the various components on the density of the polyester sample is clearly seen. It is seen that the density of the reference sample is $23.2 \mathrm{Kgm}^{-3}$; reducing/increasing the percentage content of toluene-diisocyanate (TDI) results in the reduction of the density of the resulting sample, the same thing is applicable when the percentage of distil water used is varied. In the case of percentage amine used in the production of the polyester sample, reducing 
Table 4. Effects of varying additive content on the indentation hardness index of the polyester sample.

\begin{tabular}{|c|c|c|c|c|}
\hline Varying Additive & $\begin{array}{l}\text { Indentation } \\
\text { to } 65 \% \\
\text { Thickness }\end{array}$ & $\begin{array}{l}\text { Hardness } \\
\text { Value }\end{array}$ & $\begin{array}{c}\text { Indentation } \\
\text { to } 60 \% \\
\text { Thickness }\end{array}$ & $\begin{array}{c}\text { Hardness } \\
\text { Value }\end{array}$ \\
\hline$-20 \%$ TDI & 31.28 & 97 & 28.87 & 100 \\
\hline$-10 \%$ TDI & 30.07 & 76 & 27.76 & 89 \\
\hline$+10 \%$ TDI & 30.10 & 163 & 27.79 & 197 \\
\hline$+20 \%$ TDI & 31.32 & 198 & 28.91 & 214 \\
\hline$-20 \%$ Distil Water & 37.26 & 193 & 34.39 & 219 \\
\hline$-10 \%$ Distil Water & 32.41 & 159 & 29.92 & 203 \\
\hline$+10 \%$ Distil Water & 30.65 & 84 & 28.29 & 112 \\
\hline$+20 \%$ Distil Water & 31.73 & 93 & 29.29 & 106 \\
\hline$-20 \%$ Amine & 31.21 & 126 & 28.81 & 137 \\
\hline$-10 \%$ Amine & 30.64 & 121 & 28.28 & 121 \\
\hline$+10 \%$ Amine & 32.03 & 127 & 29.57 & 127 \\
\hline$+20 \%$ Amine & 32.14 & 131 & 29.67 & 145 \\
\hline $\begin{array}{c}-20 \% \text { Stannous } \\
\text { Octoate }\end{array}$ & 28.73 & 139 & 26.52 & 152 \\
\hline $\begin{array}{c}-10 \% \text { Stannous } \\
\text { Octoate }\end{array}$ & 29 & 131 & 26.77 & 138 \\
\hline $\begin{array}{c}+10 \% \text { Stannous } \\
\text { Octoate }\end{array}$ & 29.45 & 128 & 27.19 & 136 \\
\hline $\begin{array}{c}+20 \% \text { Stannous } \\
\text { Octoate }\end{array}$ & 28.93 & 134 & 26.7 & 147 \\
\hline$-20 \%$ Silicone oil & 29.05 & 124 & 26.81 & 134 \\
\hline$-10 \%$ Silicone oil & 28.73 & 122 & 26.52 & 119 \\
\hline$+10 \%$ Silicone oil & 29.88 & 123 & 27.58 & 115 \\
\hline$+20 \%$ Silicone oil & 30.81 & 121 & 28.44 & 133 \\
\hline Reference Sample & 41.03 & 151 & 37.87 & 167 \\
\hline
\end{tabular}

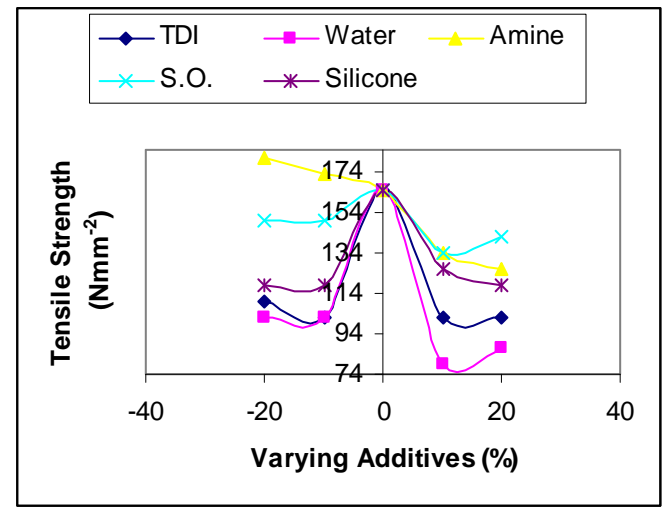

Figure 2. Effect of varying additives on the tensile strength of the polyester sample.

the content of amine results in reduction of the density of the polyester, while increasing the content of amine results in increased density of the polyester samples. Moreover, reducing the percentage content of stannous octoate in the polyester content results in increase density also increasing the content of stannous octoate results in slight increase in the density of resulting sample [17]. For silicone oil, reducing/increasing the percentage content of silicone results in the reduction of the density of the resulting sample.

Furthermore, from Table 3, Figures 2 and 3, the effect of varying the components of the polyester samples on their tensile properties is elucidated. It is seen that the tensile strength of the reference sample is $165.4 \mathrm{Nmm}^{-2}$; reducing/increasing the percentage content of toluenediisocyanate (TDI) results in the reduction of the tensile strength of the resulting sample, the same trend is observed when the percentage of distil water used is varied. In the case of percentage amine used in the production of the polyester sample, reducing the content of amine results in an increment in the tensile strength of the polyester, while increasing the content of amine results in reduction in tensile strength of the polyester samples. Moreover, similar to what was observed in TDI, reducing/increasing the percentage content of stannous octoate in the polyester content results in reduction in the tensile strength of resulting samples. For silicone oil, reducing/ increasing the percentage content of silicone results in the reduction of the tensile strength of the resulting samples. From Figure 3, the percentage elongation of the reference sample is 129.7 , reducing the percentage content of TDI in the polyester samples results in an increment in the elongation of the sample while increasing the TDI content in the samples results in a reduction in the elongation to failure of the resulting polyester samples. For the other additives, the maximum elongation is observed in the reference sample; that is reducing or increasing the percentage content of the other additive results in reduction in the elongation (ductility) of the resulting polyester samples.

Moreover, Table 4 and Figure 4 show clearly the effect of varying the content of the various additives of the indentation hardness values of the various resulting samples. The values of the indentation hardness samples indented to $65 \%$ and $60 \%$ of the samples' thickness were

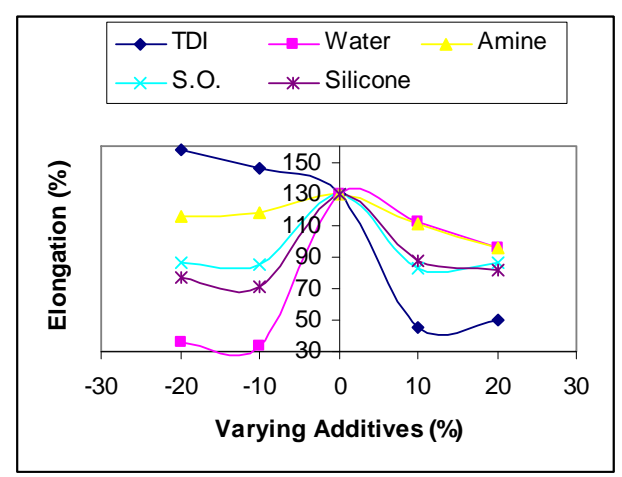

Figure 3. Effect of varying additives on the percentage elongation of the polyester sample. 
Table 5. Effects of varying additive content on the compression set of the polyester sample.

\begin{tabular}{|c|c|c|c|}
\hline $\begin{array}{l}\text { Varying } \\
\text { Additive }\end{array}$ & $\begin{array}{c}\text { Initial } \\
\text { Thickness } \\
\text { (cm) }\end{array}$ & $\begin{array}{c}\text { Final } \\
\text { Thickness } \\
(\mathrm{cm})\end{array}$ & $\begin{array}{l}\text { Compression } \\
\text { Set Value (\%) }\end{array}$ \\
\hline$-20 \%$ TDI & 2.51 & 1.35 & 46.2 \\
\hline$-10 \%$ TDI & 2.51 & 1.62 & 35.5 \\
\hline$+10 \%$ TDI & 2.51 & 2.28 & 9.2 \\
\hline$+20 \%$ TDI & 2.51 & 2.21 & 11.9 \\
\hline$-20 \%$ Distil Water & 2.51 & 2.25 & 10.4 \\
\hline$-10 \%$ Distil Water & 2.51 & 2.26 & 9.9 \\
\hline$+10 \%$ Distil Water & 2.51 & 1.97 & 21.5 \\
\hline$+20 \%$ Distil Water & 2.51 & 2.04 & 18.7 \\
\hline$-20 \%$ Amine & 2.51 & 2.31 & 7.9 \\
\hline$-10 \%$ Amine & 2.51 & 2.29 & 8.8 \\
\hline$+10 \%$ Amine & 2.51 & 2.25 & 10.4 \\
\hline$+20 \%$ Amine & 2.51 & 2.22 & 11.6 \\
\hline $\begin{array}{c}-20 \% \text { Stannous } \\
\text { Octoate }\end{array}$ & 2.51 & 2.15 & 14.3 \\
\hline $\begin{array}{c}-10 \% \text { Stannous } \\
\text { Octoate }\end{array}$ & 2.51 & 2.07 & 17.5 \\
\hline $\begin{array}{c}+10 \% \text { Stannous } \\
\text { Octoate }\end{array}$ & 2.51 & 2.04 & 18.7 \\
\hline $\begin{array}{c}+20 \% \text { Stannous } \\
\text { Octoate }\end{array}$ & 2.51 & 2.05 & 18.3 \\
\hline$-20 \%$ Silicone oil & 2.51 & 2.28 & 9.2 \\
\hline$-10 \%$ Silicone oil & 2.51 & 2.27 & 9.6 \\
\hline$+10 \%$ Silicone oil & 2.51 & 2.16 & 13.9 \\
\hline$+20 \%$ Silicone oil & 2.51 & 2.19 & 12.7 \\
\hline Reference Sample & 2.51 & 2.23 & 11.2 \\
\hline
\end{tabular}

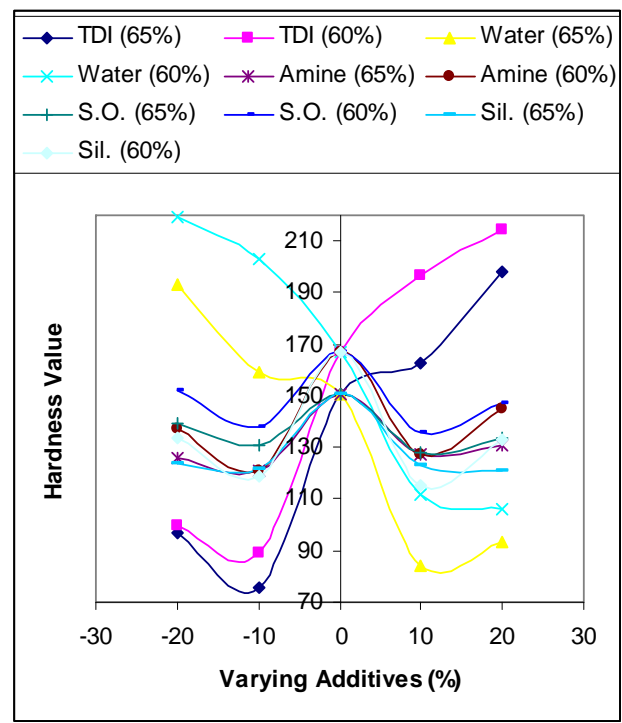

Figure 4. Effect of varying additives on the hardness of the polyester sample.

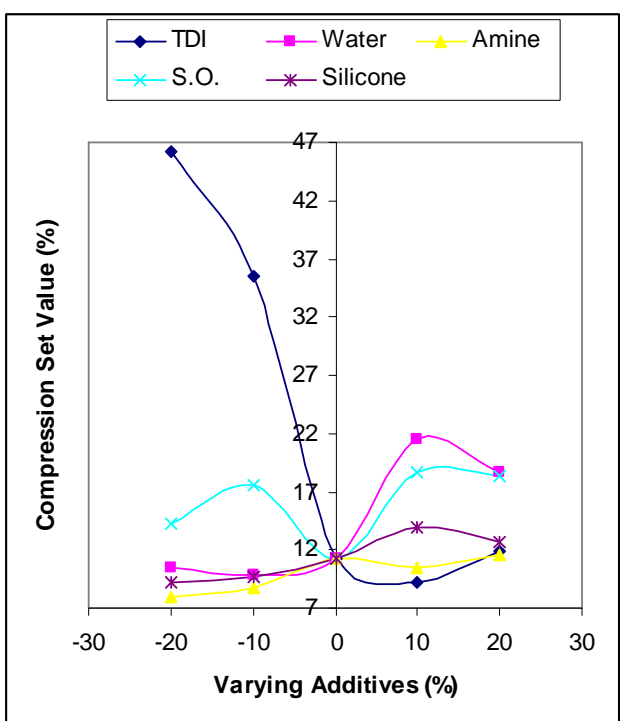

Figure 5. Effect of varying additives on the compression set value of the polyester sample.

plotted against the percentage composition of the various additives. It is observed that when the samples were indented to $65 \%$ of the thickness, the reference sample has the indentation hardness of 151 and when the samples were indented to $60 \%$ of the samples' thickness the reference sample has the indentation hardness of 167. For both cases, reducing the TDI content in the samples reduces the hardness values of the polyester samples while increasing the TDI content of the samples increases the hardness values of the polyester samples. Conversely, reducing the water content increases the hardness values of the samples, while increasing the water content reduces the hardness values of the polyester samples. For other additives, the highest value of indentation hardness in both cases is observed in the reference sample; reducing/increasing the percentage content of other additives results in reduction of the indentation hardness values.

From Table 5 and Figure 5, the compression set value of the reference sample is 11.2, reducing the TDI content in the polyester sharply increases the compression set values of the polyester samples increasing the TDI content in the samples slightly reduces the compression set value and then begins to increase slightly. In the case of distil water, amine and silicone oil, the compression set values of the samples reduced with reduction in the content of the respective additive and increased with increase of the same. The shape of the graph relating the relationship between the compression set of the sample and percentage content of stannous octoate is sinusoidal. With the exception of TDI, the range of compression set values resulting from varying the percentage content of the additives falls within acceptable range [17]. The compression set value obtained by reducing the percentage content of TDI was outside the acceptable range but as 
the TDI content is increased, it falls within the acceptable range.

\section{Conclusion}

From the observations discussed it can be concluded that:

- With the exception of amine and stannous octoate, all the other additives have values at which the density is optimum, and these values produced the optimum density of $23.2 \mathrm{Kgm}^{-3}$. The density of the foam samples increases with decrease or increase in the percentage content of stannous octoate used. The density of the polyester samples also increases with increased percentage content of amine.

- With the exception of amine, the tensile strength of the polyester samples decreases with decrease/increase in the percentage content of all the other additives. The optimum tensile strength coincides with that of the reference sample for various percentage contents of all other additives. The tensile strength of the samples reduces with increase in percentage content of amine.

- With the exception of TDI, the elongation of the polyester samples decreases with decrease/increase in the percentage content of all the other additives. The optimum tensile strength coincides with that of the reference sample for various percentage contents of all other additives. The elongation of the samples reduces with increase in percentage content of TDI.

- With the exception of TDI and distil water, the indentation hardness of the polyester samples decreases with decrease/increase in the percentage content of all the other additives. The optimum indentation hardness coincides with that of the reference sample for various percentage contents of all other additives. The indentation hardness of the samples reduces with increase in percentage content of distil water and increases with increase in TDI.

- The degree of indentation affects the value of indentation hardness; the higher the degree of indentation, the higher the indentation hardness value.

- Increasing the percentage content of TDI results in acceptable compression set value for the polyester samples.

- Holding all other parameters constant, reducing the water content and increasing the TDI content will yield polyester foam of optimum properties.

\section{REFERENCES}

[1] J. W. Nicholson, "The Chemistry of Polymers," 2nd Edition, The Royal Society of Chemistry, Athe Naeum Press, London, 1997, pp. 133-136.

[2] M. Surendra Kumar, N. Sharma and B. C. Ray, "Struc- tural Integrity of Glass/Polyester Composites at Liquid Nitrogen Temperature," Journal of Rein-forced Plastics and Composites, Vol. 28, No. 11, 2009, pp. 1297-1304. http://dx.doi.org/10.1177/0731684408088889

[3] N. Mallick, "Composite Materials Technology, Processes and Properties," Hanser Publishers, Munchen, 1990.

[4] C. H. Hare, "Protective Coatings," 1994, pp. 149-163.

[5] M. Rojek and J. Stabik, "The Influence of X-Rays on Strength Properties of Polyester Vascular System Prosthesis," Journal of Achievements in Materials and Manufacturing Engineering, Vol. 35, No. 1, 2009, pp. 47-54.

[6] S. B. Abdessalem, S. Mokhtar, H. Bellaissia and B. Durand, "Mechanical Behavior of a Textile Polyester Vascular Prosthesis: Theoretical and Experimental Study," Textile Research Journal, Vol. 75, No. 11, 2005, pp. 784788. http://dx.doi.org/10.1177/0040517505057168

[7] N. Blanchemain, T. Laurent, F. Chai, Ch. Neut, S. Haulon, V. Krump-Konvalinkova, M. Morcellet, B. Martel, C. J. Kirkpatrick and H. F. Hildebrand, "Polyester Vascular Prostheses Coated with a Cyclodextrin Polymer and Activated with Antibiotics: Cytotoxicity and Microbiological Evaluation," Acta Biomaterialia, Vol. 4, No. 6, 2008, pp. $1725-1733$.

http://dx.doi.org/10.1016/j.actbio.2008.07.001

[8] A. Cardon, N. Chakfé, F. Thaveau, E. Gagnon, O. Hartung, S. Aillet, Y. Kerdiles, Y.-M. Dion, J.-G. Kretz and Ch. J. Doillon, "Sealing of Polyester Prostheses with Autologous Fibrin Glue and Bone Marrow," Annals of Vascular Surgery, Vol. 14, No. 6, 2000, pp. 543-552. http://dx.doi.org/10.1007/s100169910102

[9] M. Balazic and J. Kopac, "Improvements of Medical Implants Based on Modern Materials and New Technologies," Journal of Achievements in Materials and Manufacturing Engineering, Vol. 25, No. 2, 2007, pp. 31-34.

[10] S. Gogolewski and G. Galletti, "Degradable, Microporous Vascular Prosthesis from Segmented Polyurethane," Colloid and Polymer Science, Vol. 264, No. 10, 1986, pp. 854 858. http://dx.doi.org/10.1007/BF01410635

[11] D. Makanjuola, "Handbook of Flexible Foam Manufacture," Temm Consulting Ltd, Nigeria, 1999.

[12] K. Uhlig, "Discovering Polyurethanes," Carl Hanser Verlag, Munich, 1999.

[13] R. Simpson, "Polymer Development—The Road Map," TCE Today, 2004.

[14] G. Woods, "The ICI Polyurethanes Book," 2nd Edition, ICI Polyurethanes and Wiley, Chichester, 1990.

[15] O. O. Ogunleye, F. A. Oyawale and G. A. Odewole, "Optimum Allocation of Silicone Oil in the Flexible Polyurethane Foam Production," Journal of Science Engineering and Technology, Vol. 8, No. 19, 2006.

[16] UT, "Global Polyurethane Industry Directory 2001," Crain Communications, London, 2000.

[17] M. O. Edoga and E. A, Egila, "Development and Characterization of Flexible Polyurethane Foam: Part I-Physicochemical and Mechanochemical Properties," Journal of Engineering and Applied Sciences, Vol. 3, No. 8, 2008, pp. 647-650. 